\title{
Forecasting water allocations for Bundaberg sugarcane farmers
}

\author{
Yvette Everingham $^{1, *}$, Craig Baillie ${ }^{2}$, Geoff Inman-Bamber ${ }^{3}$, Justine Baillie $^{4}$ \\ ${ }^{1}$ School of Mathematics, Physics and Information Technology, James Cook University, Townsville, Queensland 4811, Australia \\ ${ }^{2}$ National Centre for Engineering in Agriculture, University of Southern Queensland, Toowoomba, Queensland 4350, Australia \\ ${ }^{3}$ CSIRO, University Road, Townsville, Queensland 4814, Australia \\ ${ }^{4}$ Former address: SunWater, PO Box 3247, Bundaberg DC, Queensland 4670, Australia
}

\begin{abstract}
Limited water availability in dry cane growing regions poses a challenge to sugarcane farmers. Water allocations tend to be lower at the beginning of the water season, and are increased during the season when inflows are captured. Probabilistic information reflecting the likelihood of specified increases in water allocation is not available to sugarcane farmers. The present paper describes how seasonal climate forecasts were used to provide this information for the 2001/2002 season as part of a case study involving sugarcane farmers in Bundaberg, Australia. Water allocation forecasts were then supplied to an irrigation simulation scheduling system to provide guidance about when and how much water could be applied. This research was underpinned by a cross-institutional collaboration that engaged industry, extension officers, engineers from the water authority and scientists from agriculture and climatology. The key findings from this investigation were 2-fold: the participatory approach (1) contributed to the development of information needed by industry, and (2) demonstrated the potential usefulness of climate forecasting models, hydrological models and cropping system simulators to contribute to enhancing knowledge about water availability and application. Additional investigations are required before this technology can be operationalised.
\end{abstract}

KEY WORDS: Adoption · Barriers · Participatory $\cdot$ Irrigation $\cdot$ Predict $\cdot$ Southern Oscillation $\cdot$ APSIM Resale or republication not permitted without written consent of the publisher

\section{INTRODUCTION}

Sugarcane grown in Queensland occupies the narrow coastal strip along the eastern coast of Australia between the latitudes of -17 and $-25^{\circ} \mathrm{S}$ (Fig. 1). Rainfall amounts along this coastal strip vary substantially from region to region and from season to season; this variability-combined with low average rainfall and limited supplies from on-farm reservoirs - presents a serious challenge to sugarcane growers in the Bundaberg region (Australia). Compared to the northern tropical canegrowing areas in Australia, rainfall is much scarcer near Bundaberg $(1092 \pm 325 \mathrm{~mm}$, mean $\pm \mathrm{SD}$ ). For example, average annual rainfall in the Bundaberg region is approximately a quarter of the average annual rainfall for the Tully sugar mill (4055 \pm $1037 \mathrm{~mm}$ ). In fact, the lowest annual rainfall recorded for Tully $(1837 \mathrm{~mm})$ is nearly double the average annual rainfall for Bundaberg. Limited water availability in drier regions poses a challenge in growing a profitable crop for harvest.

Sugarcane farmers (particularly in the drier regions) must give careful consideration to the irrigation regime they implement in any particular growing season. Specifically, growers contemplate how much water to use and when this should be applied. Crop models that describe the biophysical interaction between the plant and the environment can assist with water management decisions. The crop simulators, APSIM (Keating et al. 1999) and CANEGRO (Inman-Bamber 2000) have been used to produce irrigation strategies for sugarcane systems (Muchow \& Keating 1998, InmanBamber et al. 2002, Inman-Bamber \& McGlinchey 2003). Irricane (Singels et al. 1998) is another example 


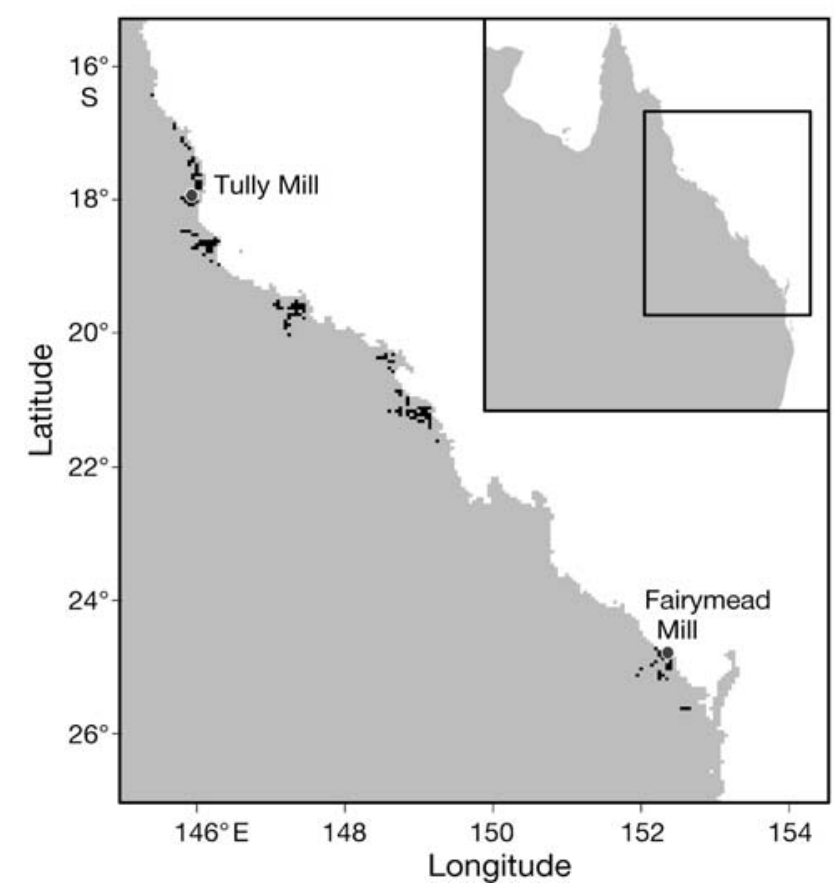

Fig. 1. Sugarcane growing regions in Queensland, Australia

of a simulation tool that has been applied in the South African sugar industry for assisting farmers with irrigation scheduling. Successful irrigation strategies produced from cropping system simulators require knowledge of water availability during the growing season.

The maximum amount of water available in a season is dependent upon water allocated by water resource managers. Water allocations are heavily dependent on the interaction between current water storage levels and future streamflows, both of which are impacted by climate variability. In Australia, especially along the eastern coast, the relationship between the El NiñoSouthern Oscillation (ENSO) and climate variability is widely recognised (Pittock 1975, McBride \& Nicholls 1983, Stone \& Auliciems 1992). It is therefore reasonable to expect that ENSO would also influence water availability.

There are a number of studies on the use of climate models for streamflow forecasting and water resource management. Everingham et al. (2002b) investigated the capability of forecasting streamflows for the Burnett River, which is a major source of water to sugarcane farmers on the Bundaberg Water Supply Scheme (BWSS). The same authors found that positive and rising southern oscillation index (SOI) phases (Stone \& Auliciems 1992, Stone et al. 1996) favour an increased probability of above-median total streamflows in the Burnett River for the period from October to December. Conversely, a negative SOI phase relates to a much lower probability of experiencing above-median streamflows for that same period. The ability to forecast streamflows for the Burnett River supported previous streamflow forecasting research. Abawi \& Dutta (1998) demonstrated shifts in the distributions of streamflow between SOI phases, and Chiew et al. (1998) demonstrated strong linkages between the ENSO phenomena and streamflows across 80 unregulated catchments in eastern Australia. Collectively, these findings show streamflows tend to be higher (lower) when the SOI is positive (negative) and/or sea surface temperatures in the central equatorial Pacific are lower (higher) than average. Chiew et al. (2003) further used the relationship between streamflows and climate prediction systems to provide irrigators with an advanced indication of the likelihood of increases in water resources through an irrigation season. This was achieved by coupling the ENSO/streamflow relationship with water allocation models used by water resource managers. Ritchie et al. (2004) have combined economic, agronomic, hydrological and climatological modelling to assist with plant-area decisions for irrigated cotton farmers in the northern Murray-Darling Basin. Ritchie et al. (2004) found that significant gains in gross margin returns can be obtained if farmers manage planting area based on seasonal climate forecasts. However, Ritchie et al. (2004) also note that a farmer's response to seasonal climate forecasting is strongly influenced by attitude to risk. Pagano \& Garen (2005) review the evolution of the integration of climate information and forecasts into the western United States water supply. The potential utility of climate forecasts to enhance flood planning management in the Pacific northwest has also been investigated (Wernstedt \& Hersh 2002). In the same region, Hamlet et al. (2002) describe the relationship between the ENSO and Pacific Decadal Oscillation signals with streamflow forecasts for the Colombia River in the United States Pacific northwest, and outline the economic benefits associated with streamflow forecasting for hydropower. One simulation highlighted that an increase in average annual revenue of US\$ 153 million could be realised from an operational system that incorporates climate forecasts.

The effect of climate variability on sugarcane irrigation scheduling has also been investigated. InmanBamber et al. (2001) showed how irrigation strategies can vary between El Niño years and La Niña years, and Everingham et al. (2002a) demonstrated how the timing of successive irrigations could be improved by using phases of the SOI. An optimization and forecasting procedure based on APSIM-Sugarcane is now available on the internet for certain regions in Australia (Inman-Bamber et al. 2005). However, probabilistic knowledge of future water availability is lacking from this procedure.

A number of studies have explored impediments to the adoption or wider application of seasonal climate 
forecasting technologies, particularly in the contexts of agricultural and water resource management (Callahan et al. 1999, Pagano et al. 2001, Pulwarty \& Melis 2001, Hartmann et al. 2002, Pagano \& Garen 2005, Ziervogel et al. 2005, Sivakumar 2006, Garbrecht \& Schneider 2007, Hayman et al. 2007). The literature brings to light several factors to be considered if the challenges associated with deriving benefits from seasonal climate forecasting innovations are to be lessened. These factors include, but are not limited to:

1. Accuracy ${ }^{\mathbf{1}}$. End users inevitably claim low accuracy levels as the reason why they do not use climate forecasts. In some situations these claims are justified, but sometimes claims of insufficient accuracy levels are made without understanding the strengths and limitations of seasonal climate forecasts, and in some cases by not distinguishing seasonal climate forecasts from other types of weather related forecasts. In many cases, however, farmers do not grasp the mathematics associated with climate forecasting and are unable to benchmark the performance of a reputable, nonperfect climate forecasting system against a 'chance' or 'no-skill forecasting system' (see point 2). Thus, there is a need to improve accuracy where appropriate and/or address the preconceived perception that forecasts are 'not accurate enough'.

2. Communicating probabilities. Forecasts are commonly issued in terms of probabilities. In order for forecasts to be more widely used there is a need to equip industry practitioners with the skills to correctly interpret and integrate probabilistic information within a decision-making framework.

3. Relevance. Forecasts need to align with the practitioner's need. For example there is no point forecasting rainfall if yield forecasts are more appropriate.

4. Resolution and frequency. A precursor to relevant forecasts is having forecasts that are at the appropriate scale and are issued at the appropriate frequency.

5. Institutional barriers. Institutional barriers can impede the progress of scientific advances and policy. Increased flexibility among institutions can facilitate the integration of seasonal climate forecasts into planning activities. An additional barrier arises from the different perspectives (on the application of seasonal climate forecasts) that researchers from different institutions typically hold. Resolution of this problem requires an awareness and understanding of opposing viewpoints from both sides.

\footnotetext{
1The literature tends to use the words 'accuracy' and 'skill' interchangeably, both of which have strict and differing climatological definitions. In this introduction we have reluctantly used the word 'accuracy' to be in line with the references provided, but note that more general terms such as forecast quality and/or forecast performance would be more appropriate in the current context.
}

6. Quantitative evidence. Need to provide quantitative evidence about the benefits of seasonal climate forecasts.

7. Information transfer. Appropriate pathways for delivering climate forecasting information need to be considered and implemented.

8. Non-adoption situations. It is important to learn from situations where farmers or managers did not adopt the forecasting technology.

The purpose of this study is to report on a collaborative cross-institutional effort (Point 5) that involved local farmers, climate researchers, agricultural researchers, extension officers and engineers from water agencies to provide relevant and practical (Point 3) forecasts for sugarcane farmers in Bundaberg, who expressed a need for information on water availability to improve productivity and profitability. This collaborative effort facilitated the integration of climate, hydrological and cropping simulation models, which led to the development of an irrigation schedule that incorporated water allocation forecasts for sugarcane farmers from Bundaberg during the 2001/2002 irrigation season. The key lessons learnt from this process and recommendations for future work are discussed. The limitations of this $1 \mathrm{yr}$ case study have also been reported.

\section{DATA AND METHODOLOGY}

\subsection{Case study}

In any given irrigation system, a significant issue for growers is knowing how much water they will have available for irrigation and when to use available water supplies. In response to this problem, collaborative research was conducted to develop irrigation strategies for the best use of limited water during the season. The research was conducted in real time, where interaction with growers occurred through irrigation discussion groups as irrigation strategies were being developed. Over 500 growers participated in these discussions. In addition to these discussion groups, a rural water-use efficiency (RWUE) committee was formed of farmers, industry council members, researchers and extension staff. The role of the RWUE committee was to prioritise issues raised from the discussion groups and to guide the research efforts of the scientific team. In addition, some members of the RWUE committee held the discussion meetings on their family farms so that discussions could be extended into field activities to motivate growers' attendance. The extension officers involved in the project were liasons for both the RWUE and the discussion groups, whilst the research team was primarily en- 
gaged with the RWUE committee. An action research approach was taken.

Action research methods, or participatory action research methods, have been discussed in depth by numerous authors and we refer the interested reader to Oquist (1978), Martin \& Sherington (1997), McTaggart (1997a,b), Carberry et al. (2002) and McCown (2002) for more details on these methods. Basically, participatory action research involves cycles of acting, observing, reflecting and revising, whereby scientists and system members who may benefit from the technology work towards a goal, learning from each other along the way.

As part of the action research cycle, industry members (i.e. those involved in the discussion groups and members of the RWUE) initially requested the research team to investigate the possibility of forecasting rainfall. When the rainfall forecasts were presented back to the RWUE committee, the members realised that the rainfall forecasts would not help irrigators manage water supplies. Instead, the RWUE suspected that streamflow forecasts would be more relevant. An assessment of the ability to forecast streamflows was therefore undertaken. Next, the industry consultative groups requested researchers to assess whether allocations could be forecast. This required collaboration between researchers, industry and water agencies to investigate, firstly, if this could be done given the formal rules and regulations surrounding water authorities, and, secondly, assuming this could be done, to develop a procedure that would produce the forecast allocations. Once allocation forecasts were determined and communicated to growers via discussion groups, growers were then interested in how the forecast allocation could be used. A methodology for producing the water allocations and irrigation schedules is described in the following subsection along with some background details about the water supply scheme.

\subsection{Water supply scheme}

SunWater is the builder, owner and operator of the water infrastructure throughout Queensland, which encompasses the case study region of this paper. Irrigation water supplies in the Bundaberg district include surface water from the BWSS and ground water from the Bundaberg subartesian area. The BWSS was designed in 1970. There are 2 main rivers contributing to the scheme - the Kolan River and the Burnett River. This study focused on irrigators accessing water from the Burnett part of the scheme, where a $100 \%$ allocation allowed growers to apply $4 \mathrm{Ml}$ (megalitres) of water for every hectare under cane, somewhat less than the optimal $6 \mathrm{Ml} \mathrm{ha}^{-1}$, as outlined in Baillie (2004).
The water year for the management of BWSS is from 1 July to 30 June. From a climate perspective, this coincides with a time period in which there is persistence in ENSO. This persistence, however, will tend to dissipate towards the end of the water year (around autumn). Each July, SunWater announces an allocation as a percentage of the entitlement volume for the current water year. As an example, a $10 \%$ allocation would be equivalent to $0.4 \mathrm{Ml} \mathrm{ha}^{-1}(40 \mathrm{~mm}$ ) for the full cropped area. Announced allocations are based on the SunWater allocation model, which incorporates available water in storage, future inflows and transmission and operating losses to determine announced allocations for irrigators. For more details on the operating rules pertaining to this study, we refer the reader to the Interim Resource Operations License provided by the regulatory authority (Queensland Government, Department of Natural Resources 2000).

Allocations cannot be reduced as the year progresses. To take account of this, SunWater takes a conservative approach in determining the water allocation. The available water resource is estimated as the present storage plus nominal inflows of $2000 \mathrm{Ml}$ for the Burnett River minus high security requirements (about $24000 \mathrm{Ml} \mathrm{yr}^{-1}$ ), a 12 mo high security carry-over and other operating and transmission losses. This allocation is revisited as water storage levels increase during the season. Noteworthy is the conservative assumption of $2000 \mathrm{Ml}$ inflow. The minimum annual recorded inflow for the Burnett River is $54546 \mathrm{Ml}$, with a median inflow of $830520 \mathrm{Ml}$. Since most inflows occur in the Austral summer (December to February), the final allocation percentage will almost always be higher than the initial allocation percentage. Despite the likely increase, the water authority is bound by the operating rules and, to avoid legal penalties, is unable to announce future allocations until the flows have been captured.

Developing irrigation strategies for a season is complicated because water is allocated to sugarcane farmers at different times during the year. Typically these allocations are lower at the beginning of the water year (July) and increase during the next $12 \mathrm{mo}$, as water inflows are captured (Fig. 2). The cycle begins again in July of the following year. Although Fig. 2 suggests the final allocation is approximately double the initial allocation, most growers do not fully understand the probability of increases in allocations and remain fearful about the downside risk associated with years when the allocation may not increase. Consequently, many farmers take a conservative view of assuming very little increase in future allocations. For example, in $2000 / 2001$ it was identified that a water volume equivalent to $15 \%$ of the nominal allocation for the BWSS was left unused at the end of the water year. Clearly, 


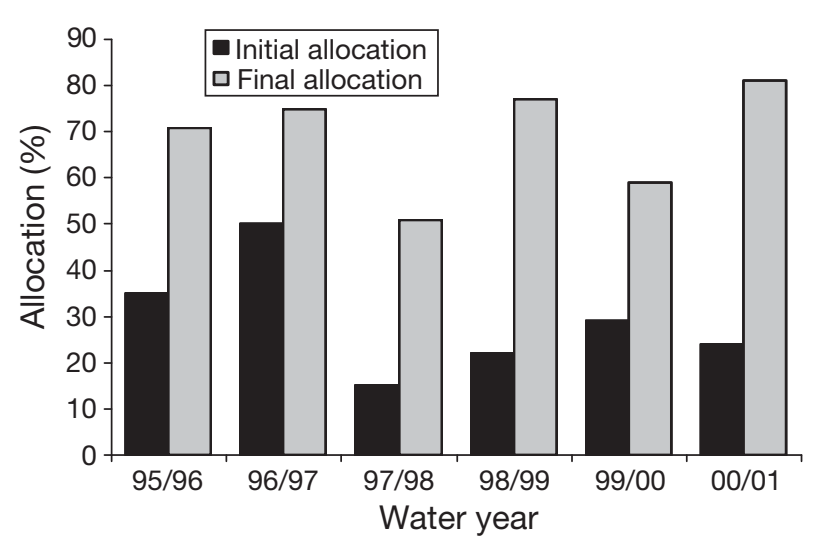

Fig. 2. Initial allocation and final allocation as a percentage of total allocation for water years between 1995 and 2000 for sugarcane farmers on the Bundaberg (Australia) water supply scheme

improved understanding of water availability for the coming season would give farmers a better sense of how much water they could use earlier in the season. This would be particularly useful for this case study where water at the end of the year is not directly redistributed to the grower who 'saved' their water.

\subsection{Climate forecasting system}

The climate forecasting system applied in the present paper is the 5 phase SOI climate forecasting system (Stone et. al. 1996). The phases of the SOI represent the change in the average SOI over consecutive months. The SOI phases are:

1. Consistently negative (neg) - the SOI stays sufficiently negative from one month to the next.

2. Consistently positive (pos) - the SOI stays sufficiently positive from one month to the next.

3. Rapidly falling (fal)-the SOI falls sufficiently from one month to the next.

4. Rapidly rising (ris) - the SOI rises sufficiently from one month to the next.

5. Near zero (nz) - the SOI stays close to zero from one month to the next.

The term 'sufficiently' is dependent on the defining boundaries from a cluster analysis and principal component procedure as described by Stone \& Auliciems (1992).

Every month since 1887 can be classified as 1 of these 5 phases. The probability of exceeding a specified value of the response is calculated by a historical analysis. The denominator in the probability fraction is the number of years that the particular SOI phase in a particular month has occurred, and the numerator is the number of years the response exceeded the specified value.

\subsection{Forecasting water allocations}

The water allocation was forecast on 2 occasions between July 2001 and June 2002. The first forecast, produced at the end of August, predicted the likely allocation at the end of December. The second forecast, produced in early January, predicted the likely allocation at the end of March. The August forecast indicated the probability of the allocation increasing mid-season. This gave growers an opportunity to plan the use of water earlier. The January forecast gave growers an opportunity to revise their initial irrigation strategies and, where appropriate, modify their strategies to be in a better position to use all of their remaining allocation as recommended by Baillie (2004).

The August allocation forecast was produced as follows:

1. Inputs to the SunWater allocation model that describe climate and hydrological conditions were set according to the conditions observed at the end of August 2001.

2. Observed historical Burnett River streamflows, for each year between 1911 and 1996, were individually entered into the SunWater allocation model for the months of September, October, November and December. The output from the model was a distribution of allocations for the end of December 2001. This distribution was produced from data on each annual streamflow sequence entered into the allocation model as depicted in Fig. 3. We define $A_{\mathrm{SEP}-\mathrm{DEC}(j)}$ to be the expected allocation at the end of 2001 if September to December streamflow sequences identical to the year $j \in[1911,1996]$ occurred.

3. The allocations produced by the model were divided into 5 groups on the basis of the August SOI phase. For example, the allocations derived from streamflows in: 1926, 1927, 1929, 1930, 1931, 1932, 1933, 1935, 1939, 1948, 1949, 1952, 1959, 1961, 1963, 1968, 1969, 1978, 1980, 1984, 1990, 1992 and 1995 formed 1 group. These years had a near zero August

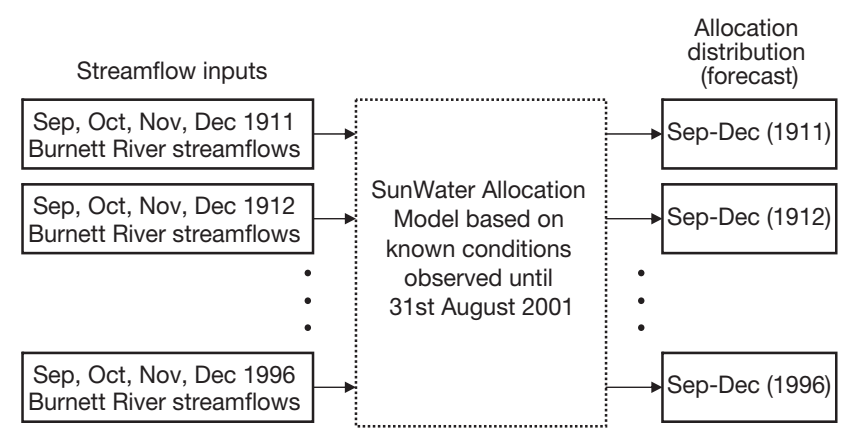

Fig. 3. Computation of the forecast allocation distribution for the end of December. This forecast distribution is based on observed conditions until 31 August 2001 and historical streamflow sequences between 1911 and 1996, inclusively 

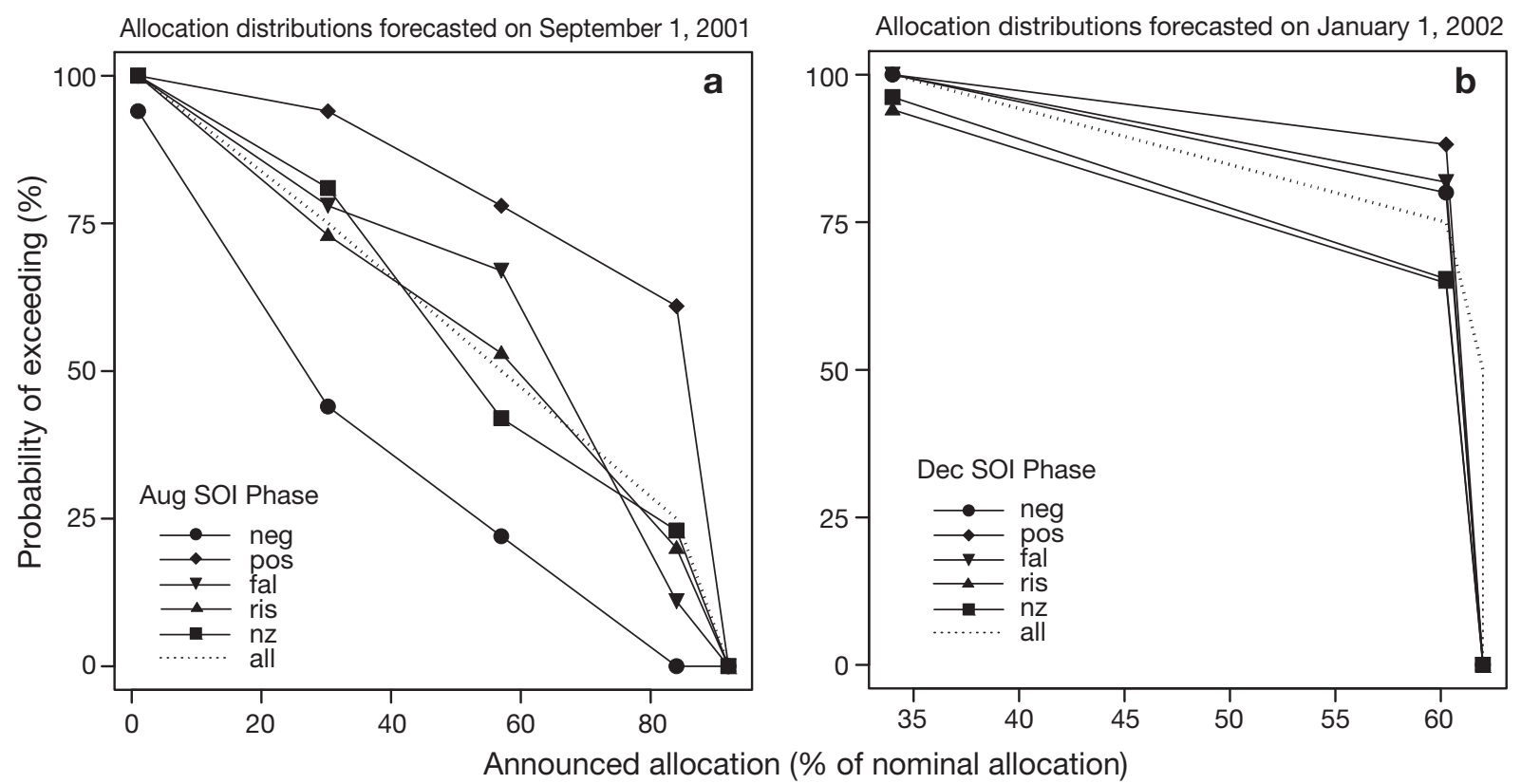

Fig. 4. Probability ( $y$-axis) that allocations at the end of (a) December and (b) March will exceed a certain amount ( $x$-axis). This amount is expressed as a percentage of a farmer's nominal allocation (4 Ml ha ${ }^{-1}$ ). These probabilities were calculated using perfect knowledge of the water system until the beginning of (a) September and (b) January. Projections were based on climatology (all years) and for years defined by the preceding (a) August and (b) December SOI (Southern Oscillation index) phases. Abbreviations in Section 2.3

SOI phase. The other 4 groups were derived similarly.

4. A graph that displayed the probability of reaching certain allocation levels by the end of December was produced (see Fig. 4a).

5. A Kruskal-Wallis test (Triola 2008) was used to investigate distributional differences of the forecast allocations by the SOI phases.

6. The January forecast was performed in a similar way to the August forecast. The SunWater allocation model was initialised to mimic observed climate and hydrological conditions at the end of December 2001. The SunWater allocation model used historical streamflow sequences for January, February and March to obtain water allocations at the end of March. The output concerning allocations from the SunWater model were separated into 5 groups according to the December SOI phase (see Fig. 4b).

\subsection{Linking forecast allocations with simulated irrigation schedules}

As part of the case study, growers became more aware of the probability of increases in water allocation. Given these likely increases growers then questioned how they could plan to use their water. To assist growers contemplating how an increased allocation could be best used, the next stage of the research process involved integrating future probabilistic knowl- edge of water availability with the APSIM-based irrigation optimization process described by InmanBamber et al. (2005). In this process APSIM was used to simulate crop growth up to the end of the current climate record when the crop may only be partially developed. Development to the anticipated harvest date is then simulated using $40 \mathrm{yr}$ of climate records for the given calendar period between the current and harvest dates. For each year in the simulation, irrigation is 'applied' at 10 levels of crop water stress until the given allocation is exhausted. In the case of no stress, the allocation rapidly depletes unless there is rainfall to help prevent stress. The greater the stress level, the longer it would take to use the given allocation. Allowing too much stress to develop may result in under-utilisation of the allocation, which can then produce suboptimal economic returns as detailed by Baillie (2004). Inman-Bamber et al. (2005) estimate water stress levels in the simulation by comparing photosynthesis with potential photosynthesis. The former may be limited by lack of water, while the latter is not limited by root water supply. A distribution of best irrigation dates was obtained from the best strategies (highest yield ${ }^{2}$ ) in each of the $40 \mathrm{yr}$ in the simulation.

\footnotetext{
2The strategy that gives the highest yield will also maximise profitability. The strategies have no cost differentiation because they are based on using the same quantity of water within the constraints of the existing irrigation infrastructure.
} 
The next irrigation was applied on the median date. The median date was chosen because the risk of irrigating too early is equal to the risk of irrigating too late. We refer the reader to Inman-Bamber et al. (2005) for more details about this procedure.

The procedure summarised above was used to develop an irrigation schedule to demonstrate to growers how they could plan to use their water for the remainder of the season. In Bundaberg, sugarcane is harvested over a 6 mo period (approximately June to November) after which the crop is ratooned (allowed to regrow). Ratoon crops regenerate any time between June and November. Two irrigation schedules were produced for growers - the first was designed for crops that ratoon early (July) and the second was specific to late (October) ratoons. Experience with the optimization system showed that soil type did not have a significant effect on the irrigation schedule. This is because the system aims to irrigate during forecasted stress periods, which occur regardless of soil type. The degree of stress during these periods is highly dependent on soil type, but the timing of the stress periods less so. A Red Kandosol (Isbell 1996) was selected to represent a range of intermediate soil types common to Australian sugarcane growing regions.

\section{RESULTS AND DISCUSSION}

Fig. 4a shows the probability of reaching various announced water allocations at the end of December 2001, based on the 5 August SOI phases individually, and combined ('all'). The 'all years' line produced by merging the 5 SOI groups showed a probability of $0.75^{\frac{3}{}}$ that the allocation would exceed $30 \%$ at the end of December. If the August SOI phase was consistently negative, then the probability of exceeding a $30 \%$ allocation would be much lower (0.40 to 0.50). Conversely, the probability of exceeding a $30 \%$ allocation is much higher ( 0.90), following a consistently positive August SOI phase. In 2001, the August SOI phase was near zero. The allocation distribution based on the near zero SOI phase is similar to the all years (climatology) lineapproximately a 0.75 probability that the allocation would exceed $30 \%\left(1.2 \mathrm{Ml} \mathrm{ha}^{-1}\right)$ by the end of December. The Kruskal-Wallis test was significant ( $p=0.001)$, supporting evidence for differences in forecast allocations among the SOI phases.

The procedure was repeated in early January, when allocations at the end of March were forecast. Fig. $4 \mathrm{~b}$ shows the allocation forecast for the end of March. The

${ }^{3}$ The 75 th percentile was chosen, as it seemed to represent amongst growers a good balance between being too risky and too conservative. second forecast that was communicated to growers via a media release highlighted a 0.75 probability that the allocation at the end of March would be $55 \%$ $\left(2.2 \mathrm{Ml} \mathrm{ha}^{-1}\right)$. When this forecast was produced, there was limited airspace in the water storage facilities to capture future inflows, and this contributed to the marked change in the shape of the probability curve and an insignificant Kruskal-Wallis test $(p=0.272)$. The variation in allocations between years with different SOI phases was therefore negated due to limited storage capacity. The rapidly falling SOI phase for December 2001 did not influence the climatological forecast.

Once growers were aware that future insight about likely allocation increases could be produced, the next question they asked was how this knowledge could be combined with irrigation management practices. As part of the action research approach, this was investigated. At the end of December 2001, growers had access to $35 \%$ of their nominal allocation (i.e. $1.4 \mathrm{Ml} \mathrm{ha}^{-1}$ ). Based on water meter readings, growers had used only $1 \mathrm{Ml} \mathrm{ha}^{-1}$ of this amount. The irrigation simulation required that APSIM was programmed to use $1 \mathrm{Ml} \mathrm{ha}^{-1}$ by the end of December, since this is what had actually happened. Based on the allocation forecast (Fig. 4b), APSIM was programmed to use an additional $1.2 \mathrm{Ml}$ $\mathrm{ha}^{-1}\left(2.2 \mathrm{Ml} \mathrm{ha}^{-1}\right.$ minus $\left.1 \mathrm{Ml} \mathrm{ha}^{-1}\right)$ by 30 June (the end of the water year). Fig. 5 shows how much water should be used ( $y$-axis) and by when ( $x$-axis) for early ratoons/ cut blocks (Fig. 5a) and late ratoons/cut blocks (Fig. 5b). Consider, for example, the irrigation schedule that maximises simulated yield (Fig. 5a). Approximately $16 \%$ of the available water is applied in November and December, and approximately $38 \%$, in January, with smaller amounts of irrigation applied after February. Thus, the irrigation schedule for early cut blocks provides an irrigation schedule that concentrates on water application from November to January, whilst, for late cut blocks (Fig. 5b), the irrigation schedule suggests that it is better to spread out water applications.

\section{CONCLUDING REMARKS}

The present paper has reported a cross-institutional collaborative effort established during the 2001/2002 water year to fulfil sugarcane farmers' requests of improving their knowledge about water availability. At the end of the study, water allocations were forecast using phases of the SOI for sugarcane farmers on the southern BWSS in Australia. Additionally, it was demonstrated how forecast allocations could be linked to an irrigation scheduling system. This entire process was a direct result of growers, extension staff, water authorities and research scientists working in participation with one another. As a whole, the industry was 


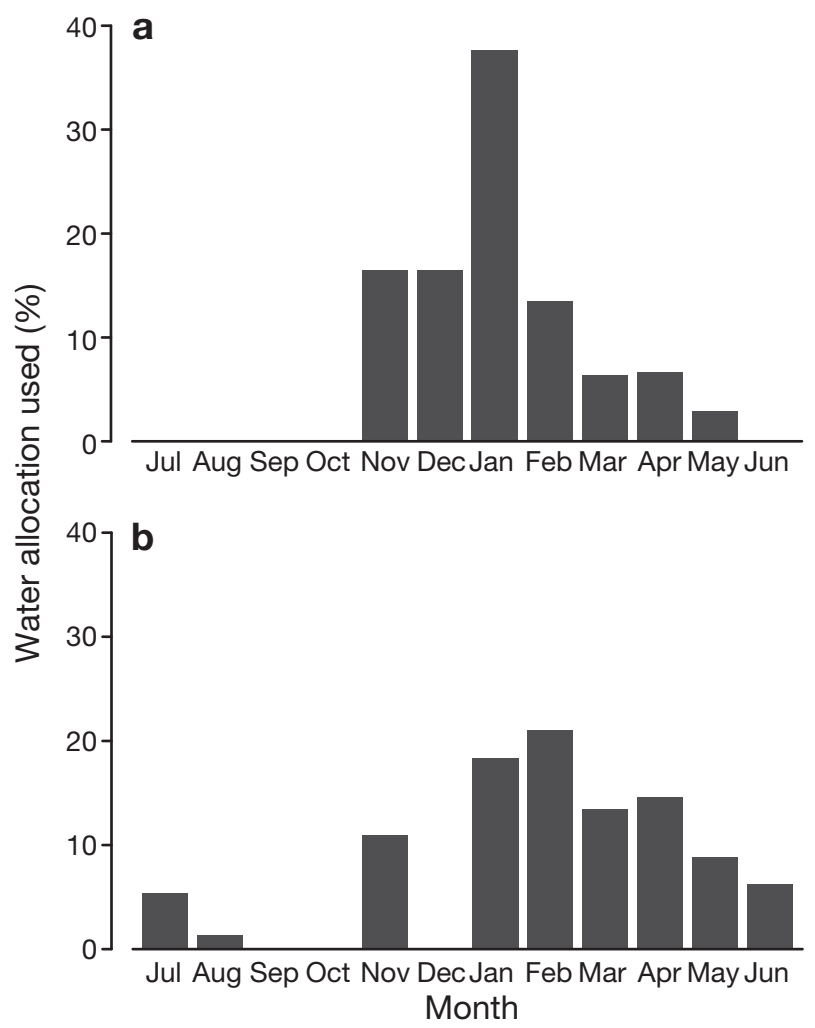

Fig. 6. Irrigation strategies for (a) early and (b) late cut blocks

simply unaware of the flexibility of modelling tools to produce relevant information for managing irrigation practices and assessing the risk of increases in future allocation announcements. Similarly, the researchers and water authorities were not aware of the precise needs of industry members. The participatory approach ensured that the researchers programmed their models to output information that was relevant to industry needs. Moreover, the symmetrical learning that was undertaken made growers aware of the outputs that could be generated from the agrological, climatological and hydrological models. Two key findings emerged from this study. The first key finding was that the participatory approach significantly contributed to the production of relevant information that matched the needs of industry stakeholders. The second key finding was that the participatory approach highlighted the potential usefulness of modelling tools and decision support systems to improve irrigators' knowledge about water availability and application.

A limitation of this research was that it did not consider the 8 points that contribute to the lack of adoption of climate forecasts (listed in the 'Introduction'). Rather it simply focused on overcoming cross-institutional barriers (Point 5) and producing relevant forecasts (Point 3). However, this was sufficient to identify what type of information irrigators need and provide a baseline methodology for delivering this information. Future research is needed to determine if the 'accuracy' (Point 1) can be improved, for example, by considering alternative forecasting systems and understanding the relationship between 'accuracy' and leadtimes. We believe the participatory research ensured that the forecasts were at the appropriate scale/resolution; however, further advice from industry about the frequency of the forecasts should be considered (Point 4). The challenge of communicating probabilities (Point 2) will always be a major obstacle to address. It is vital that future work formally assesses the quantitative benefits (Point 6) of the forecasting methodology and considers appropriate pathways for information transfer (Point 7). Perhaps, however, the first thing to be done should be to review the literature in order to learn from non-adoption situations (Point 8).

Some technologically driven findings also emerged from this case study. Whilst future work is needed to improve the methodological process, the process as it stands played a significant role in increasing awareness about the need to use more water early, and the high probability of increases in water allocations throughout the season. It is important to reinforce that the ability of climate forecasts to improve upon climatology is dependant on both the SOI phase and the current hydrological conditions, e.g. storage availability. Interestingly, the forecasting system was found to be a trigger for increasing awareness and understanding about fundamental patterns in the water system derived from climatological increases in water allocations. Prior to this case study, this information was unknown and a process for producing this information was undefined.

In response to grower demand, allocations were again forecast in the 2002/2003 water year. In early 2003, the BWSS received significant inflow, filling storages to a point where the announced allocation for the scheme was increased to $100 \%$. For the several years that followed, the announced allocation remained at $100 \%$, and therefore allocation forecasts have not been required. However, the sustained drier periods that have been witnessed since 2003 have bought this research to the fore again.

Acknowledgements. This research was funded in part by the Australian government through the Sugar Research and Development Corporation, the Climate Variability and Agriculture Program and the RWUE Initiative. Y.E. was employed by CSIRO at the time this research was undertaken. The authors thank the Bundaberg RWUE Committee for their fruitful discussions in identifying how seasonal climate forecasts could be used to enhance irrigation management in the Bundaberg region. Thanks are also extended to D. Zamykal for assisting with the preparation of this manuscript. We acknowledge DNRM for providing access to the streamflow data and SunWater for undertaking allocation predictions. 


\section{LITERATURE CITED}

Abawi GY, Dutta SC (1998) Forecasting of stream-flows in NEAustralia based on the Southern Oscillation Index. In: Proc Int Conf on Engineering in Agriculture, Perth, Western Australia (27-30 September). Paper SEAg 98/067, Institute of Engineers Australia

Baillie CP (2004) Strategies for maximising sugarcane yield with limited water in the Bundaberg district. MS thesis, University of Southern Queensland, Toowoomba

$>$ Callahan B, Miles E, Fluharty D (1999) Policy implications of climate forecasts for water resources management in the Pacific Northwest. Policy Sci 32:269-293

Carberry PS, Hochman Z, McCown RL, Dalgliesh NP and others (2002) The FARMSCAPE approach to decision support: farmers', advisers', researchers' monitoring, simulation, communication and performance evaluation. Agric Syst 74:141-177

Chiew FHS, Piechota TC, Dracup JA, McMahon TA (1998) El Niño/Southern Oscillation and Australian rainfall, streamflow and drought: links and potential for forecasting. J Hydrol 204:138-149

Chiew FHS, Zhou SL, McMahon TA (2003) Use of seasonal streamflow in water resources management. J Hydrol 270: 135-144

Everingham YL, Muchow RC, Stone RC, Inman-Bamber NG, Singels A, Bezuidenhout CN (2002a) Enhanced risk management and decision-making capability across the sugar industry value chain based on seasonal climate forecasts. Agric Syst 74:459-477

Everingham YL, Inman-Bamber NG, Smith DM (2002b) Seasonal climate forecasts to enhance decision making capability across the sugar industry value chain. In: Bruce RC (ed) Proc Aust Soc Sugar Cane Technol 24:67-74 Scribe Consulting, Brisbane

Garbrecht JD, Schneider JM (2007) Climate forecast and prediction product dissemination for agriculture in the United States. Aust J Agric Res 58:966-974

Hamlet AF, Huppert D, Lettenmaier DP (2002) Economic value of long-lead streamflow forecasts for Columbia River hydropower. J Water Res Plann Manag 128:91-101

Hartmann HC, Pagano TC, Sorooshian S, Bales R (2002) Confidence builders: evaluating seasonal climate forecasts from user perspectives. Bull Am Meteorol Soc 83:683-698

Hayman P, Crean J, Mullen J, Parton K (2007) How do probabilistic seasonal climate forecasts compare with other innovations that Australian farmers are encouraged to adopt? Aust J Agric Res 58:975-984

Inman-Bamber NG (2000) History of the CANEGRO model. In: O'Leary GJ, Kiker GA (eds) Proc 1st Int Workshop on the Canegro sugarcane model, Mount Edgecombe, South Africa, 4-7 August 2000, South African Sugar Technologists Association, Mount Edgecombe, p 5-8

Inman-Bamber NG, McGlinchey MG (2003) Crop coefficients and water-use estimates for sugarcane based on long-term Bowen ratio energy balance measurements. Field Crops Res 83:125-138

Inman-Bamber NG, Everingham YL, Muchow RC (2001) Modelling water stress response in sugarcane: validation and application of the APSIM-sugarcane model. In: Proc 10th Aust Agron Conf. The Australian Society of Agronomy, Hobart

Inman-Bamber NG, Baillie C, Willcox J (2002) Tools for improving efficiency of limited water use in sugarcane. In: Sutton BG (ed) Proc Irrig Assoc Aus Natl Conf, Sydney, 21-23 May 2002, Irrigation Association of Australia, Hornsby, p 251-259

Inman-Bamber NG, Attard SA, Baillie C, Lawson D, Simpson L (2005) A web-based system for planning use of limited irrigation water in sugarcane. Aust Soc Sugar Cane Technol

Editorial responsibility: Joan Kleypas,

Boulder, Colorado, USA
$27: 170-181$

Isbell RF (1996). The Australian soil classification. In: Australian soil and land survey handbook, Vol 4. CSIRO Publishing, Melbourne

Keating BA, Robertson MJ, Muchow RC, Huth NI (1999) Modelling sugarcane production systems. Development and performance of the sugarcane module. Field Crops Res 61:253-271

> Martin A, Sherington J (1997) Participatory research methods-implementation, effectiveness and institutional context. Agric Syst 55:195-216

McBride JL, Nicholls N (1983) Seasonal relationships between Australian rainfall and the southern oscillation. Mon Weather Rev 111(1822):1998-2003

> McCown RL (2002) Changing systems for supporting farmers' decisions: problems, paradigms, and prospects. Agric Syst 74:179-220

McTaggart R (1997a) Guiding principles for participatory action research. In: McTaggart R (ed) Participatory action research: international contexts and consequences. State University of New York Press, Albany, p 25-45

McTaggart R (1997b) Reading the collection. In: McTaggart R (ed) Participatory action research: international contexts and consequences. State University of New York Press, Albany, p 1-24

Muchow RC, Keating BA (1998) Assessing irrigation requirements in the Ord Sugar Industry using a simulation modelling approach. Aust J Exp Agric 38:345-354

Oquist P (1978) The epistemology of action research. Acta Sociol 21:143-163

Pagano TC, Garen DC (2008) Integration of climate information and forecasts into western US water supply forecasts. ASCE Monograph on the use of climate information in water management. J Am Water Res Assoc (in press)

Pagano TC, Hartmann HC, Sorooshian S (2001) Using climate forecasts for water management: Arizona and the 19971998 El Niño. J Am Water Resour Assoc 37:1139-1153

Pittock AB (1975) Climatic change and the patterns of variation in Australian rainfall. Search 6:498-504

Pulwarty RS, Melis TS (2001) Climate extremes and adaptive management on the Colorado River: lessons from the 1997-1998 ENSO event. J Environ Manage 63:307-324

Queensland Government, Department of Natural Resources (2000) Interim resources operations licence for Bundaberg water supply scheme issued to SunWater. Available at www.sunwater.com.au (accessed on November 2000)

Ritchie JW, Abawi GY, Dutta SC, Harris TR, Bange M (2004) Risk management strategies using seasonal climate forecasting in irrigated cotton production: a tale of stochastic dominance. Aust J Agr Resour Econ 44:247-257

Singels A, Kennedy AJ, Bezuidenhout CN (1998) Irricane: a simple computerised irrigation scheduling method for sugarcane. S Afr Sugar Technol Assoc 72:117-122

Sivakumar MVK (2006) Climate prediction and agriculture: current status and future challenges. Clim Res 33:3-17

Stone RC, Auliciems A (1992) SOI phase relationships with rainfall in eastern Australia. Int $\mathrm{J}$ Climatol 12:625-636

Stone RC, Hammer GL, Marcussen T (1996) Prediction of global rainfall probabilities using phases of the Southern Oscillation Index. Nature 384:252-255

Triola MF 2008. Elementary statistics, 10th edn. Pearson Education, Boston, MA

Wernstedt K, Hersh R (2002) Climate forecasts in flood planning: promise and ambiguity. J Am Water Resour Assoc 38:1703-1713

Ziervogel G, Bithell M, Washington R, Downing T (2005) Agent-based social simulation: a method for assessing the impact of seasonal climate forecast applications among smallholder farmers. Agric Syst 83:1-26 